\title{
The Mechanical Properties of Steel-Polypropylene Fibre Composites Concrete (HyFRCC)
}

\author{
Izni Syahrizal Ibrahim ${ }^{2, a}$, Wan Amizah Wan Jusoh ${ }^{1,2, b, *}$, \\ Abdul Rahman Mohd Sam ${ }^{2, \mathrm{c}}$, Nur Ain Mustapa ${ }^{2, \mathrm{~d}}$, Sk Muiz Sk Abdul Razak ${ }^{2, \mathrm{e}}$ \\ ${ }^{1}$ Faculty of Civil \& Environment Engineering, UniversitiTun Hussein Onn Malaysia, 86400 Parit \\ Raja, Johor, Malaysia.
}

${ }^{2}$ Faculty of Civil Engineering, Universiti Teknologi Malaysia, 81310 Johor Bahru, Johor, Malaysia.

aiznisyahrizal@utm.my, bamizah@uthm.edu.my, cabdrahman@utm.edu.my, ${ }^{d}$ nurainsafiya91@gmail.com, ${ }^{\mathrm{e}}$ skmuiz86@gmail.com

*Corresponding Author: amizah@uthm.edu.my

Keywords:Hybrid; steel fibre; polypropylene fibre; mechanical properties; composite concrete

\begin{abstract}
This paper discusses the experimental results on the mechanical properties of hybrid fibre reinforced composite concrete (HyFRCC) containing different proportions of steel fibre (SF) and polypropylene fibre (PPF). The mechanical properties include compressive strength, tensile strength, and flexural strength. SF is known to enhance the flexural and tensile strengths, and at the same time is able to resist the formation of macro cracking. Meanwhile, PPF contributes to the tensile strain capacity and compressive strength, and also delay the formation of micro cracks. Hooked-end deformed type SF fibre with $60 \mathrm{~mm}$ length and fibrillated virgin type PPF fibre with $19 \mathrm{~mm}$ length are used in this study. Meanwhile, the concrete strength is maintained for grade C30. The percentage proportion of SF-PPF fibres are varied in the range of $100-0 \%, 75-25 \%, 50-50 \%$, $25-75 \%$ and $0-100 \%$ of which the total fibre volume fraction $\left(V_{f}\right)$ is fixed at $0.5 \%$. The experimental results reveal that the percentage proportion of SF-PPF fibres with 75-25\% produced the maximum performance of flexural strength, tensile strength and flexural toughness. Meanwhile, the percentage proportion of SF-PPF fibres with $100-0 \%$ contributes to the improvement of the compressive strength compared to that of plain concrete.
\end{abstract}

\section{Introduction}

Fibre reinforced concrete (FRC) has been studied over the last few decades because it is found to improve the failure mode and increase the resistance of plain concrete. Plain concrete is known as a brittle material, weak in tension and have low resistance to cracking. This can be overcome by adding short discontinuous or fibrillated fibres such as synthetic, steel, natural, and glass fibres in concrete. Each type of fibre lends different properties and benefits to the concrete. Apart from being used as reinforcement, fibres are also effective in arresting cracks from forming and propagating at micro cracks and macro cracks level [1]. Fibre helps to reduce the widening of crack because of the mechanical bond between the cement paste and fibre [2]. Fibre added in concrete has also been found to be effective in controlling cracking due to plastic shrinkage and drying shrinkage [3].

The presence of more than one type of fibres in concrete can further enhance the mechanical properties compared to the existing single type fibre in a single mixture. This can be achieved by fully utilizing the properties of each fibre effectively in the concrete mixture. In this study, the combined fibres in concrete are known as hybrid fibre reinforced concrete composite (HyFRCC). The failure mode of HyFRCC is not abrupt. This is because the load carrying capacity beyond the first crack increases when the randomly oriented fibres crossing the cracked section resisted the cracks from spreading and avoid the section from splitting [4]. The strength of concrete increases with the addition of steel fibres, but in order to produce concrete with homogenous tensile properties, the formation of micro cracks must be eliminated. Synthetic fibre such as polypropylene 
fibre (PPF) is effective to reduce the formation of micro crack, whereas steel fibre (SF) is found good for arresting macro crack. Figure 1 shows how the hybridization of fibres can control the formation of micro and macro cracks.
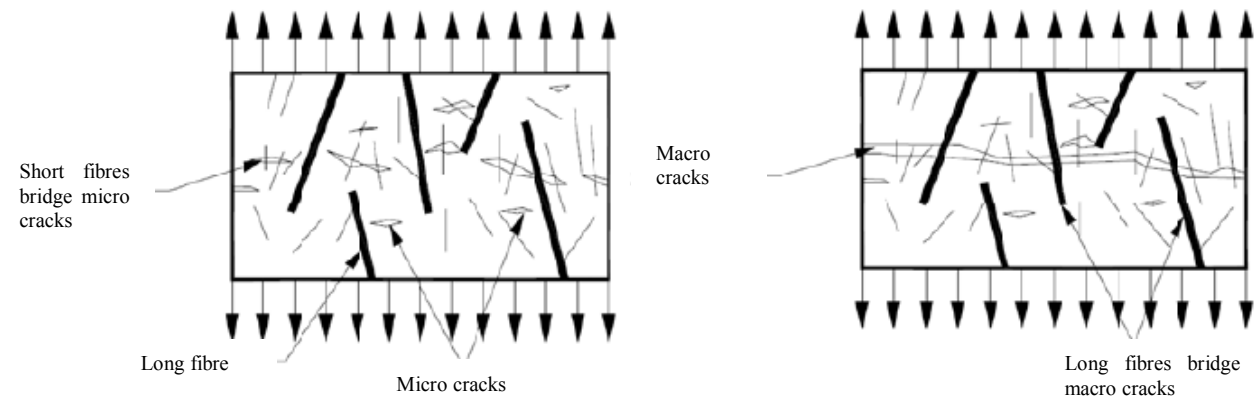

Figure 1: Actions of hybrid fibres in controlling micro and macro cracks (Bentur \&Mindess, 1990).

Fibres such as PPF when added in concrete will reduce the compressive strength, but at the same time increase both the tensile and flexural strengths [5]. Meanwhile, SF offers improve tensile strength by the increase ductility, reduce crack formation and increase fatigue resistance [6]. Therefore, combining SF and PPF in plain concrete may improve the mechanical properties of concrete [7], which is also the main concern of this study. Therefore, the main objective of this study is to determine the mechanical properties of HyFRCC which combines SF and PPF in concrete.

\section{Experimental Work}

Design Mix of HyFRCC. Six (6) concrete batches are produced and tested at fresh and hardened state. The first batch is the control specimen where no fibres are added to the concrete. The other five (5) batches are HyFRCC with different proportion of SF and PPF, where the total volume fraction is fixed at $V_{f}=0.5 \%$. SF with $60 \mathrm{~mm}$ long and PPF with $19 \mathrm{~mm}$ long are used in this study. All concrete batches have the same amount of cement, fine aggregates coarse aggregates, water, and super plasticizer. The water-to-cement ratio is 0.55 for all concrete batches. The total amount of SF and PPF based on the different percentage proportion is shown in Table 1.

Table 1: Concrete mix proportion

\begin{tabular}{|c|c|c|c|c|c|c|c|c|c|}
\hline 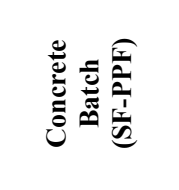 & 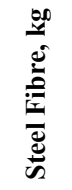 & 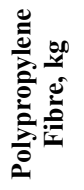 & 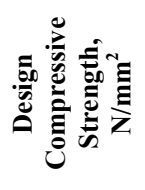 & 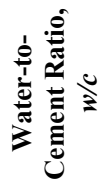 & 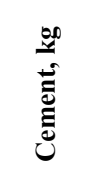 & 量 & 造 & 赵 & 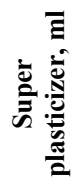 \\
\hline PC (Control) & 0.00 & 0.00 & \multirow{6}{*}{30} & \multirow{6}{*}{0.55} & \multirow{6}{*}{40.95} & \multirow{6}{*}{81.40} & \multirow{6}{*}{66.60} & \multirow{6}{*}{22.50} & \multirow{6}{*}{250} \\
\hline $\mathrm{SF}(100-0)$ & 3.03 & 0.00 & & & & & & & \\
\hline $\mathrm{Hy}(75-25)$ & 2.27 & 0.13 & & & & & & & \\
\hline Нy(50-50) & 1.51 & 0.09 & & & & & & & \\
\hline $\mathrm{Hy}(25-75)$ & 0.76 & 0.04 & & & & & & & \\
\hline $\operatorname{PPF}(0-100)$ & 0.00 & 0.17 & & & & & & & \\
\hline
\end{tabular}

Mechanical Properties Tests. At 28 days, three (3) mechanical properties tests are carried out to determine the compression strength, tensile strength and flexural strength. For this purpose, cubes of $150 \times 150 \times 150 \mathrm{~mm}$, cylinders of $150 \mathrm{~mm}$ diameter $\times 300 \mathrm{~mm}$ height, prisms of $100 \times 100 \times 500$ $\mathrm{mm}$ are prepared for each set of tests. The tests are carried out in accordance to BS EN 12390-3: 2009 for the compressive strength, BS12390-6:2009 for the tensile strength and BS12390-5:2009 for the flexural strength. 


\section{Result and Discussion}

Experimental Results at Fresh State. Figure 2 shows the relationship between the concrete slump and the fibre percentage proportion. In this study, the concrete slump is designed between $60 \mathrm{~mm}$ and $180 \mathrm{~mm}$. The relationship shows a descending pattern when fibres are added in concrete. However, they are still in the range of the design slump. This shows that adding SF and PPF in concrete will reduce the concrete workability by bridging the concrete and causing congestion in the mixture. The addition of SF and PPF decreases the slump height from $85 \mathrm{~mm}$ for the control to 61 mm for HyFRCC.

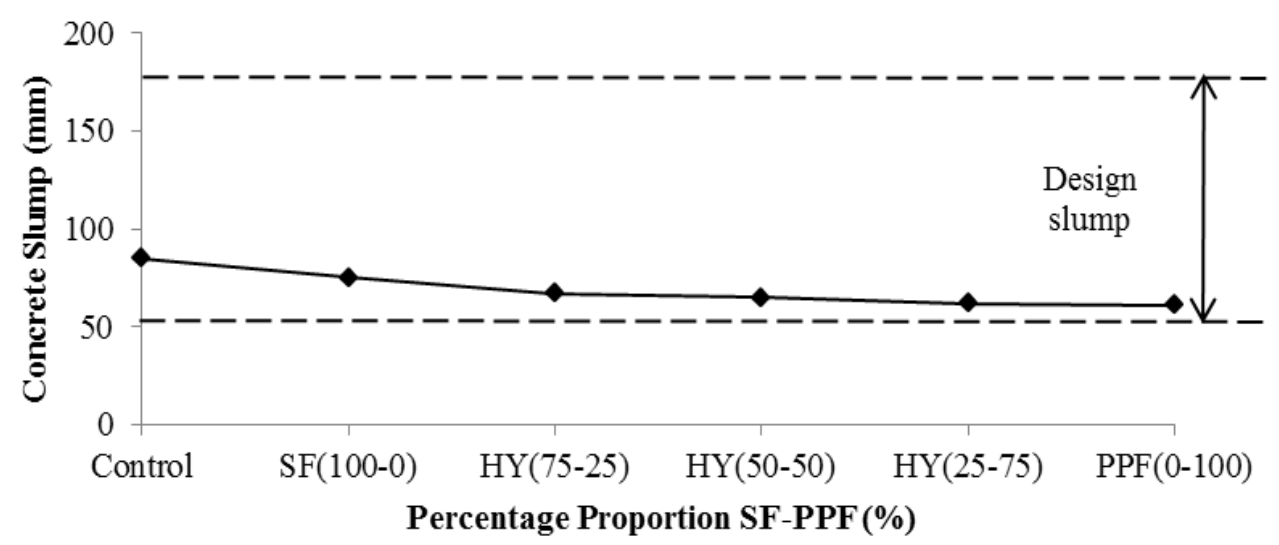

Figure 2: Relationship between concrete slump and fibre percentage proportion

Experimental Results at Hardened State. Table 2 summarized the mechanical properties results of HyFRCC and the control mix. The results are also represented in graph as shown in Figure 3 and 4. Figure 3 shows the relationship between the compressive strength and the percentage proportion of SF-PPF. Meanwhile, the values in Table 2 are based on the average of three cubes. The relationship shows that there is no significant change in the compressive strength. However, the compressive strength of $\mathrm{SF}(100-0)$ is $11.35 \%$ higher than the control. Meanwhile, $\mathrm{Hy}(75-25)$, $\mathrm{Hy}(50-50)$ and $\mathrm{Hy}(25-75)$ show a decrease of $0.13 \%, 5.60 \%$ and $4.18 \%$, respectively of the compressive strength as compared with the control. There is a further $17.43 \%$ decrease of the compressive strength for PPF(0-100) than the control. The findings suggested that HyFRCC does not have significant effect on the improvement of the compressive strength. The improvement can only be seen when using single SF indicated by the results of SF(100-0).

The tensile strength of SF (100-0) increases by $8.55 \%$ as compared with the control. This relationship is shown Figure 4. For $\operatorname{Hy}(75-25), \operatorname{Hy}(50-50)$ and $\mathrm{Hy}(25-75)$, there is an increase of $17.11 \%, 6.78 \%$ and $12.09 \%$, respectively as compared with the control. However, for $\operatorname{PPF}(0-100)$, which is PPF alone, there is a slight decrease of $1.18 \%$. Based on this findings, Hy(75-25) with $17.11 \%$ increase is recommended as the optimum fibre percentage proportion. The finding shows that HyFRCC improves the tensile strength as compared with the control and even the single fibre mixture.

From Figure 4, the flexural strength of $\mathrm{SF}(100-0)$ increases by $3.90 \%$ compared with the control. Meanwhile, Hy(75-25) shows an increase of $10.20 \%$. However, as the PPF percentage proportion increases, there is a slight decrease in flexural strength as compared with the control. For $\mathrm{Hy}(50-50), \mathrm{Hy}(25-75)$ and $\operatorname{PPF}(0-100)$, the percentage difference to that of the control is $-4.45 \%$, $2.78 \%$, and $2.04 \%$, respectively. It is observed that there is a sudden decrease from $10.20 \%$ to $-4.45 \%$ for $\mathrm{Hy}(75-25)$ and $\mathrm{Hy}(50-50)$. However, the percentage difference increases again from $\mathrm{Hy}(50-50)$ to $\mathrm{PPF}(0-100)$. The study suggested that $\mathrm{Hy}(75-25)$ with percentage increase of $10.20 \%$ produced better flexural resistance as compared with the other batches. This is also similar with the results of the tensile strength. The sudden decrease in flexural strength for $\operatorname{PPF}(0-100)$ is maybe due to the non-uniform fibre distribution in the specimen. The concrete specimens except the control did not break into two parts at failure. Therefore, the test results show that the hybridization process 
improved both the tensile and flexural strengths as compared with single fibre mixture or plain concrete.

Table 2: Result of the compressive strength, flexural strength test and tensile test

\begin{tabular}{|c|c|c|c|c|c|c|}
\hline \multirow{2}{*}{$\begin{array}{c}\text { Concrete } \\
\text { Batch }\end{array}$} & \multicolumn{2}{|c|}{$\begin{array}{c}\text { Compressive Strength, } \\
\boldsymbol{f}_{c u}\end{array}$} & \multicolumn{2}{c|}{ Tensile Strength, $\boldsymbol{f}_{c t}$} & \multicolumn{2}{c|}{ Flexural Strength, $\boldsymbol{f}_{\boldsymbol{t}}$} \\
\cline { 2 - 7 } (SF-PPF) & $\mathbf{N} / \mathbf{m m}^{\mathbf{2}}$ & $\begin{array}{c}\text { \% Difference } \\
\text { with PC }\end{array}$ & $\mathbf{N} / \mathbf{m m}^{\mathbf{2}}$ & $\begin{array}{c}\text { \% Difference } \\
\text { with PC }\end{array}$ & $\mathbf{N} / \mathbf{m m}^{2}$ & $\begin{array}{c}\text { \% Difference } \\
\text { with PC }\end{array}$ \\
\hline $\mathrm{PC}($ Control) & 38.78 & 0.00 & 3.39 & 0.00 & 5.39 & 0.00 \\
\hline $\mathrm{SF}(100-0)$ & 43.18 & 11.35 & 3.68 & 8.55 & 5.60 & 3.90 \\
\hline $\mathrm{Hy}(75-25)$ & 38.73 & -0.13 & 3.97 & 17.11 & 5.94 & 10.20 \\
\hline $\mathrm{Hy}(50-50)$ & 36.61 & -5.60 & 3.62 & 6.78 & 5.15 & -4.45 \\
\hline $\mathrm{Hy}(25-75)$ & 37.16 & -4.18 & 3.80 & 12.09 & 5.24 & -2.78 \\
\hline $\mathrm{PPF}(0-100)$ & 32.02 & -17.43 & 3.35 & -1.18 & 5.28 & -2.04 \\
\hline
\end{tabular}

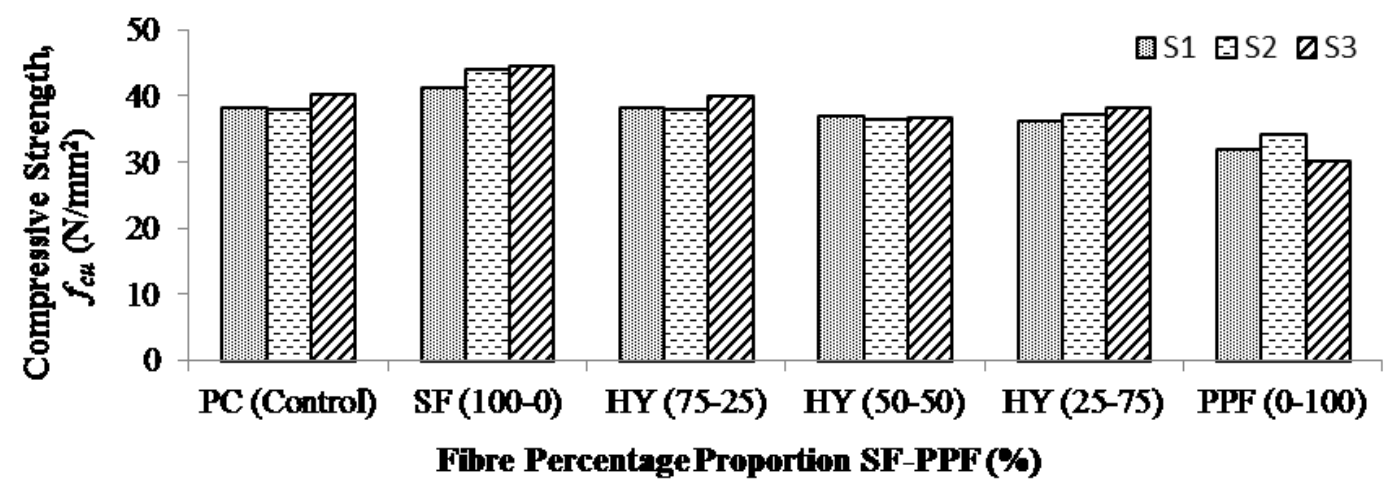

Figure 3: Relationship between compressive strength $\left(f_{c u}\right)$ and fibre percentage proportion (\%)

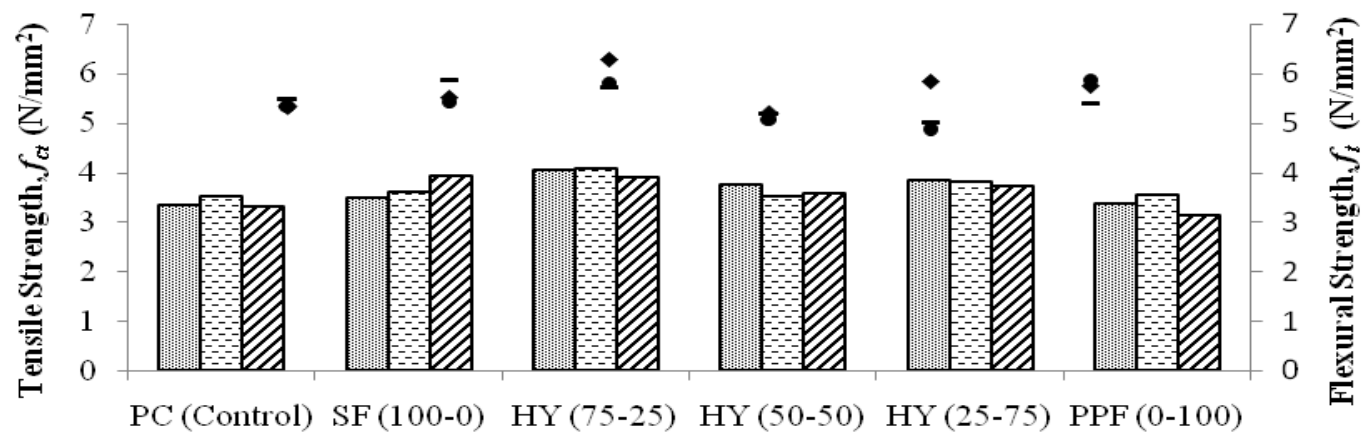

Fibre Percentage Proportion SF-PPF (\%)

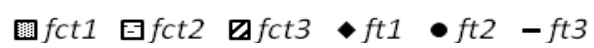

Figure 4: Relationship between the flexural strength $\left(f_{t}\right)$, tensile strength $\left(f_{c t}\right)$ and fibre percentage proportion $(\%)$

\section{Conclusion}

Experimental tests have been carried out on a different percentage proportion of SF and PPF in concrete to investigate the mechanical properties of HyFRCC. Based on the test results obtained, conclusions can be made as follows:

(i) The workability of fresh concrete is found to decrease when the percentage of fiber increase.

Too much fibre in concrete will produce low workability due to congestion. 
(ii) Fibres in concrete help to bridge crack, thus, reduce the crack growth. The combination of $\mathrm{Hy}(75-25)$ gives the highest value in flexural and tensile strengths with an increase of $17.11 \%$ and $10.20 \%$, respectively from the control. Meanwhile, SF $(100-0)$ contributes in the compressive strength. This shows that HyFRCC are less significant in compression even though they enhance the tensile and flexural strengths. From the experimental work, the control prism specimens abruptly splits into two parts at failure, while for HyFRCC, the failure is not sudden and it can still carry additional load at ultimate load capacity.

\section{Acknowledgement}

This research is funded by the Research University Grant (RUG) No. 09H36. Invaluable appreciation goes to technicians in the Structural and Material Laboratory, Faculty of Civil Engineering, Universiti Teknologi Malaysia, and the scholarship from Ministry of Education Malaysia and Universiti Tun Hussein Onn Malaysia.

\section{References}

[1] Bentur, A. and Mindess,S. (1990). "Fiber Reinforced Cementitious Composites". Elsevier Applied Science, London.

[2] Patel, P.A., Desai, A.K., Desai, A.J. (2012) . "Evaluation of Engineering Properties for Polypropylene Fiber Reinforced Concrete". International Journal of Advanced Engineering Technology, 31 42-45.

[3] Banthia, N. and Gupta, R., (2006) . "Influence of Polypropylene fiber geometry on plastic shrinkage cracking in concrete". Cement and Concrete Research. 367 1236-1267. doi: 10.1016/j. cemconres. 2006.01.010.

[4] Dilip, P., and Remadevi, K., (2014) "A Study on Properties of Hybrid Fiber Reinforced Concrete". International Journal of Software and Hardware Research in Engineering, 23 47-51.

[5] Ramezanianpour, A.A., Esmaeili, M., Ghahari, S.A., and Najafi, M.H. (2013). "Laboratory Study on the Effect of Polypropylene Fiber on Durability Physical and Mechanical Characteristic of Concrete for Application in Sleepers". Construction and Building Materials. 44 411-418.

[6] Vairagede, V.S. and Kene, K.S. (2012). "Experimental Investigation on Hybrid Fibre Reinforced Concrete". International Journal of Engineering Research and Application, 23 10371041.

[7] Qian C.X., and Stroeven, P., (2000). "Development of Hybrid Polypropylene-Steel Fiber Reinforced Concrete". Cement and Concrete Research. 301 63-69. 